\title{
WORK STRESS AND THE RISK OF RECURRENT CORONARY HEART DISEASE EVENTS: A SYSTEMATIC REVIEW AND META-ANALYSIS
}

JIAN LI ${ }^{1,2}$, MIN ZHANG ${ }^{3}$, ADRIAN LOERBROKS ${ }^{1}$, PETER ANGERER ${ }^{1}$, and JOHANNES SIEGRIST ${ }^{4}$

${ }^{1}$ University of Düsseldorf, Düsseldorf, Germany

Institute of Occupational and Social Medicine, Centre for Health and Society, Faculty of Medicine

${ }^{2}$ University of Düsseldorf, Düsseldorf, Germany

Institute of Medical Sociology, Centre for Health and Society, Faculty of Medicine

${ }^{3}$ Kunming Medical University, Kunming, China

Department of Cardiology, First Affiliated Hospital

${ }^{4}$ University of Düsseldorf, Düsseldorf, Germany

Senior Professorship on Work Stress Research, Life-Science Centre

\begin{abstract}
Though much evidence indicates that work stress increases the risk of incident of coronary heart disease (CHD), little is known about the role of work stress in the development of recurrent CHD events. The objective of this study was to review and synthesize the existing epidemiological evidence on whether work stress increases the risk of recurrent CHD events in patients with the first CHD. A systematic literature search in the PubMed database (January 1990 - December 2013) for prospective studies was performed. Inclusion criteria included: peer-reviewed English papers with original data, studies with substantial follow-up ( $>3$ years), end points defined as cardiac death or nonfatal myocardial infarction, as well as work stress assessed with reliable and valid instruments. Meta-analysis using random-effects modeling was conducted in order to synthesize the observed effects across the studies. Five papers derived from 4 prospective studies conducted in Sweden and Canada were included in this systematic review. The measurement of work stress was based on the DemandControl model (4 papers) or the Effort-Reward Imbalance model (1 paper). According to the estimation by meta-analysis based on 4 papers, a significant effect of work stress on the risk of recurrent CHD events (hazard ratio: 1.65, 95\% confidence interval: 1.23-2.22) was observed. Our findings suggest that, in patients with the first CHD, work stress is associated with an increased relative risk of recurrent $\mathrm{CHD}$ events by $65 \%$. Due to the limited literature, more well-designed prospective research is needed to examine this association, in particular, from other than western regions of the world.
\end{abstract}

Key words:

Work stress, Recurrence, Coronary heart disease, Meta-analysis, Epidemiology, Prospective studies

The paper was presented at the 6th ICOH International Conference on Work Environment and Cardiovascular Diseases; 2013 Mar 27-30; Tokyo, Japan.

This review work was partly supported by the National Natural Science Foundation of China (Project No. 81360040) and the Natural Science Foundation of Yunnan Province, China (Project No. 2013FB140). Manager of project: Min Zhang, MD, PhD.

J. Siegrist was supported by a Senior Professorship grant from the Faculty of Medicine, University of Düsseldorf, Germany. All authors declare that there is no conflict of interest.

Received: February 26, 2014. Accepted: March 28, 2014.

Corresponding author: J. Li, Institute of Occupational and Social Medicine, Centre for Health and Society, Faculty of Medicine, University of Düsseldorf, Düsseldorf 40225, Universität Strasse 1, Germany (e-mail: lijian1974@hotmail.com). 


\section{INTRODUCTION}

Coronary heart disease (CHD) is one of the leading causes of disability and death worldwide, contributing largely to the global burden of disease [1,2]. Based on a large number of prospective cohort studies, psychosocial stress has been identified to increase the risk of CHD in initially healthy populations [3-6]. Furthermore, several psychosocial factors, such as depression [7], anxiety [8], type D personality [9] and financial stress [10,11], are also observed to be predictive of the prognosis of CHD.

Given the observation of increasing incidence rates of CHD among relatively young age groups, particularly in the working population [2,12], contribution of psychosocial work stress to the development and prognosis of CHD in employed people has been drawing increasing attention. Cumulative evidence shows that psychosocial stress at work is repeatedly associated with elevated risks of fatal and non-fatal CHD, and the strongest evidence comes from the investigations that assessed an adverse psychosocial work environment in terms of psychometrically validated measurements based on stress-theoretical models, such as the Demand-Control model or the Effort-Reward Imbalance model [13-16]. The 1st model claims that stress-related ill health results from the combined effects of high job demand and low job control [17], while the latter model emphasizes harmful effects of failed reciprocity between effort spent at work and reward received in turn (high effort/ low reward) [18]. So far, few studies have analyzed the role of an adverse psychosocial work environment in the prognosis of cardiac outcomes among patients who survived their first CHD manifestation. As their findings are inconsistent [19-22], we aimed at exploring the current evidence more thoroughly by conducting a systematic review and meta-analysis of the studies that meet defined quality criteria (see below). By doing so, we hope to derive some suggestions that may instruct future research on the topic.

\section{MATERIAL AND METHODS}

In order to perform a systematic review and meta-analysis of epidemiological studies we applied internationally established guidelines [23,24]. We searched the PubMed database by applying the following inclusion criteria:

- time of publication - January 1990 - December 2013,

- study design - a prospective cohort study,

- peer-reviewed English-language article with original data,

- study subjects - patients with the 1st CHD,

- work stress - assessed with reliable and valid instruments,

- end points - cardiac death or nonfatal myocardial infarction,

- follow-up duration - more than 3 years,

- adjustment for relevant confounding factors - such as age, gender, behavior factors, clinical features of $\mathrm{CHD}$, etc.

We performed literature search using (combinations of) the following medical subject headings and key words: work stress, psychosocial work characteristics, job strain, effort reward imbalance, coronary heart disease, myocardial infarction, recurrent, patients, prognosis, death.

Random-effects modeling was used to perform meta-analysis [25]. We distinguished different levels of work stress and set a group of subjects with a low work stress level as a reference group. Then hazard ratios (HRs) and 95\% confidence intervals (CIs) associated with a high work stress level from the selected studies were estimated. We used the Q-test for heterogeneity of the study results [26]. To detect publication bias we explored the funnel plot and the degree of asymmetry by using the Begg's method [27]. Data for different measures of work stress were analyzed separately in a 1st step, then these measures were combined. In addition, all the individual psychosocial work factors defining the theoretical models were identified and included in a further set of analyses for the purpose of a detailed exploration. All analyses were conducted using 
statistical program Stata 11 (Stata Corporation, College Station, Texas, USA) [28].

\section{RESULTS}

Based on our literature search, we identified 7 papers derived from 5 prospective studies on associations between work stress and risk of recurrent CHD events [19-22,29-31]. After carefully reading all full texts of the papers, the study of Hlatky et al. was excluded due to the fact that the baseline population was not recruited according to the defined criteria. More specifically, in this study, the subjects with a history of myocardial disease were excluded, as coronary angiography, rather than a clinically defined CHD event, was used to define "coronary artery disease" [19], thus, producing some discordance between the included patient groups [32,33].

We also excluded the study by Leander et al. This paper is based on a prospective study in Sweden, which actually generated 2 publications $[21,30]$. As both papers were based on the same definition of work stress and included a largely overlapping sample with only 1 year difference in the follow-up observation time, we excluded the study with the shorter observation period from our analysis [30]. However, in another case where 2 papers were produced from 1 prospective study in Canada [22,31], both papers were included in our review for the following reasons. First, the 2 papers were based on different measures of work stress, and 2nd, clearly different periods of followup observation were defined. Therefore, 5 papers derived from 4 prospective studies were included into our systematic review (see Table 1).

Among them, 3 studies were conducted in Sweden, and 1 study was from Canada. As far as gender is concerned, 1 study was conducted exclusively among men, and 1 study was restricted to women, whereas the other 3 studies included both men and women. Questionnaires based on the Demand-Control model [34,35], were used to measure work stress in 4 papers, and the EffortReward Imbalance questionnaire [36,37] was applied in 1 paper. The follow-up time varied from 4.0 to 8.5 years. Population of the 5 papers based on 4 prospective studies included 1840 patients with the 1st CHD, and 412 cases of recurrent CHD events. Due to the incomplete statistical information ( $p=0.017$, without reporting HR and 95\% CI), the earliest study [29] was not included into this meta-analysis. Therefore, remaining 1778 patients with the 1st CHD and 399 cases of recurrent CHD events were finally taken into account.

Figure 1 presents associations between work stress and risk of recurrent CHD events. The pooled analysis for job strain, the measure of the Demand-Control model, indicated a $61 \%$ increased risk $(\mathrm{HR}=1.61$, 95\% CI: 1.14-2.28) while, the measure of the alternative work stress model, Effort-Reward Imbalance, was associated with a hazard ratio of 1.75 (95\% CI: 0.99-3.08). However, it should be kept in mind that this latter result is based on one single study. Summing up the results, a significant effect of work stress on the risk of recurrent CHD events (HR $=1.65,95 \%$ CI: $1.23-2.22, \mathrm{p}=0.001$ ) was observed. Given the limited number of studies, it was not feasible to perform gender-stratified analyses.

In the case of the individual psychosocial work factors defined by the 2 work stress models, the pooled HR for high demand and low control indicated elevated risks of $42 \%$ and $44 \%$, respectively, suggesting that the effect of job strain was produced, to some extent, by additive interaction between high demand and low control. In the case of high effort and low reward, respective risks of recurrent CHD events were increased by $17 \%$ and by $77 \%$, respectively, and thus, indicating that the reward component exerted primary contribution to the model of Effort-Reward Imbalance.

The Q-test did not indicate heterogeneity between the selected studies for this meta-analysis ( $p=0.965)$, and we found no evidence of publication bias in any analyses using funnel plot or the Begg's asymmetry method ( $p=0.734)$. 


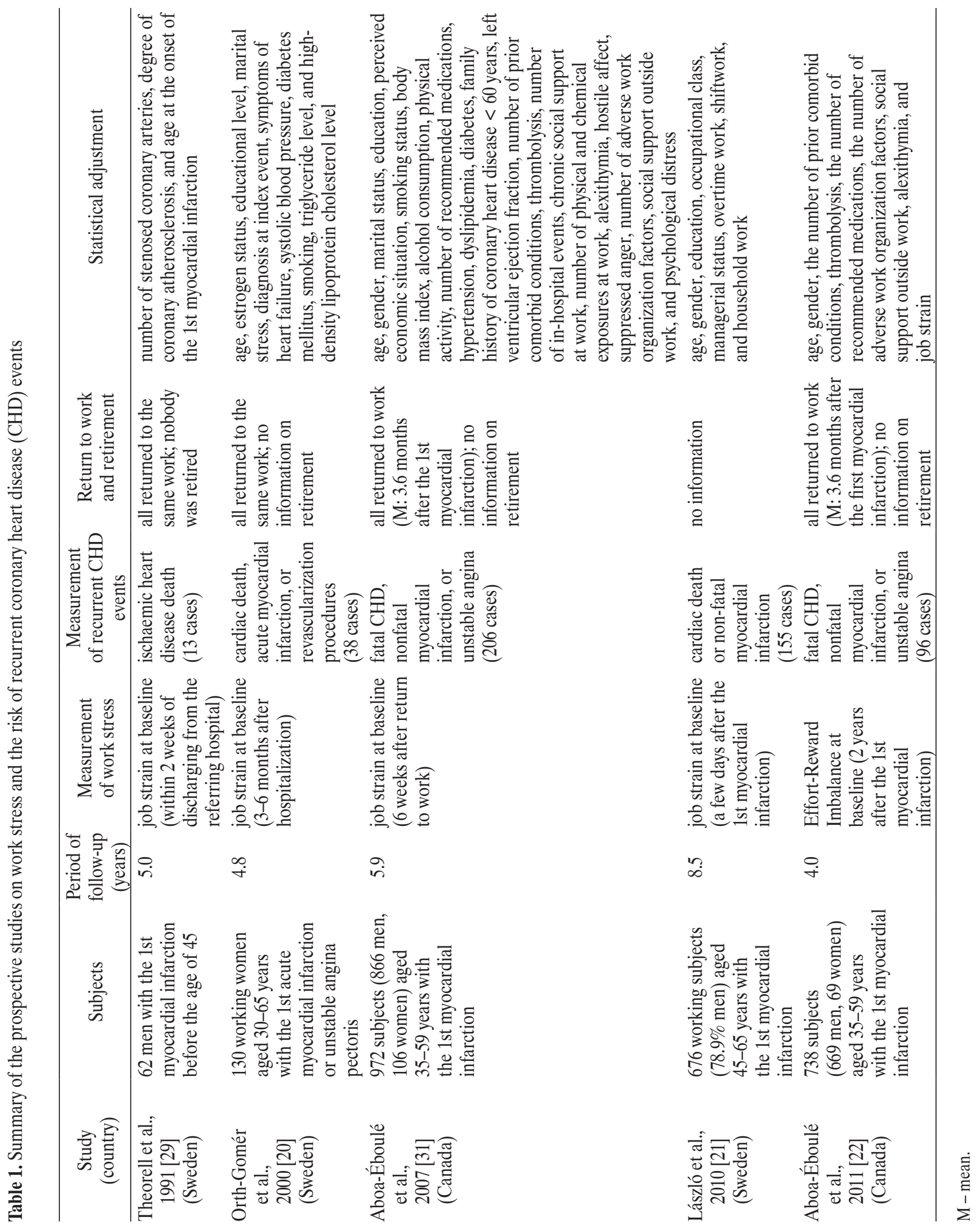


Job Strain

Orth-Gomér et al., 2000 [20] (Swedish women)

Aboa-Éboulé et al., 2007 [31] (Canadian men and women)

László et al., 2010 [21] (Swedish men and women)

Subtotal

Effort-Reward Imbalance

Aboa-Éboulé et al., 2011 [22] (Canadian men and women)

Subtotal

Work stress

Overall

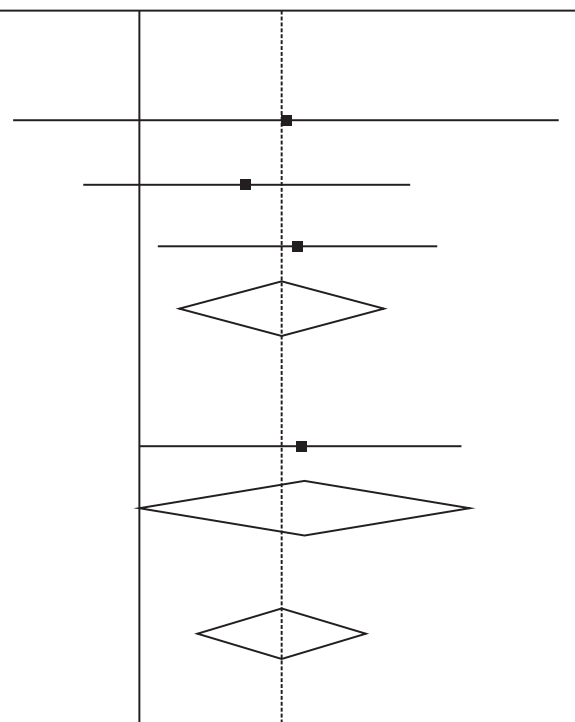

$1.67(0.64-4.32)$

$1.45(0.82-2.58)$

$1.73(1.06-2.83)$

$1.61(1.14-2.28)$

$1.75(0.99-3.08)$

$1.75(0.99-3.08)$

$1.65(1.23-2.22)$

High demand

Orth-Gomér et al., 2000 [20] (Swedish women)

Aboa-Éboulé et al., 2007 [31] (Canadian men and women)

László et al., 2010 [21] (Swedish men and women)

Overall

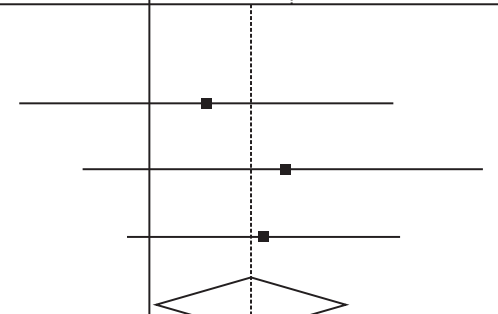

$1.21(0.63-2.32)$

$1.59(0.79-3.19)$

$1.47(0.92-2.37)$

$1.42(1.02-1.99)$

Low Control

Orth-Gomér et al., 2000 [20] (Swedish women)

Aboa-Éboulé et al., 2007 [31] (Canadian men and women)

László et al., 2010 [21] (Swedish men and women)

Overall

High effort

Aboa-Éboulé et al., 2011 [22] (Canadian men and women)

Aboathouléetal, 2011 [22] (Canadlan men and women)

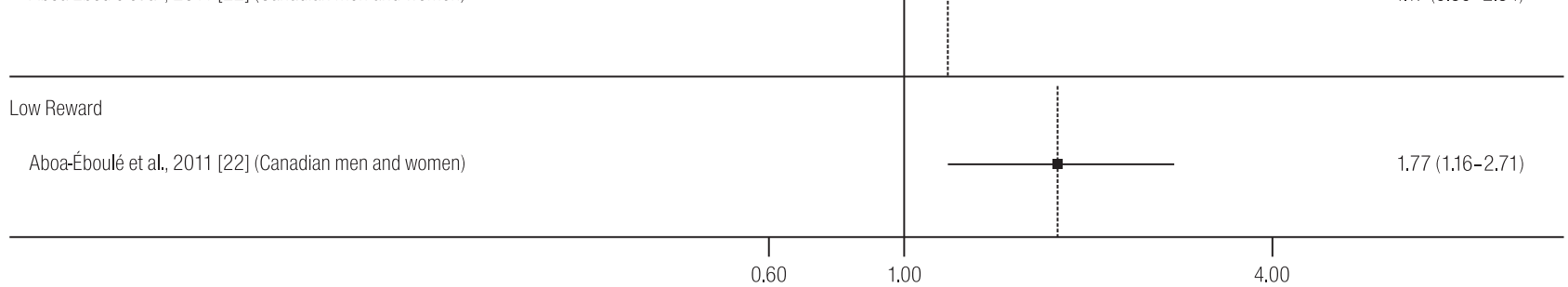

HR - hazard ratio; CI - confidence interval.

Fig. 1. Associations between work stress and the risk of recurrent coronary heart disease events 


\section{DISCUSSION}

To our knowledge, this is the first systematic review and meta-analysis concerning association between work stress and prognostic cardiac outcomes in patients who survived their first CHD event. Although based on a limited number of studies, our results suggest that work stress increases the relative risk of recurrent $\mathrm{CHD}$ events to a significant extent (i.e., $\mathrm{HR}=1.65$ ).

Several explanations have been proposed to account for the observed association. On one hand, distinct stressphysiological processes may be triggered by recurrent exposure to an adverse psychosocial work environment, with harmful effects on a compromised myocardium, such as excessive activation of the autonomic nervous system and the neuro-endocrine stress axis of the body [38,39]. For instance, a decreased heart rate variability, a marker of sympathetic overdrive, and increased levels of cortisol secretion, a marker of a dysregulated hypothalamic-pituitary adrenocortical stress axis, were observed to precede major adverse cardiovascular events in CHD patients [40,41]. In addition to neuronal and neuro-hormonal factors, several indicators of the reduced immune competence due to chronic work stress [42] may contribute to an increased susceptibility to recurrent cardiac events. Recently, also a low serum level of interleukin-17 was found to be associated with a higher risk of major cardiovascular events in CHD patients [43].

On the other hand, work stress can affect the cardiovascular system through significant changes in behavioral factors that matter for cardiovascular health, such as the increased amount of cigarette smoking or alcohol consumption, altered dietary habits or reduction of physical activity [44]. Moreover, disrupted sleep patterns and an increased prevalence of depression/anxiety induced by work stress and onset of a CHD event may matter as these latter conditions were shown to increase the risk of recurrent cardiac events $[7,8,45,46]$. While all these proposed explanations are in line with available evidence on the risk and protective factors of $\mathrm{CHD}$, to our knowledge, no single study has yet combined data on work stress, physiological markers, behavioral patterns and cardiac outcomes in a prospective design.

The results of our review and meta-analysis should be interpreted with caution for a number of limitations of the evidence. The first limitation concerns variations in return to work after the onset of the first CHD. Except for one Swedish study [21], all the remaining studies included in this review provided robust information that all the studies' participants returned to work. Cumulative evidence indicates that severity of the disease, high level of work stress, and low level of job satisfaction are the major risk factors for non-return to work following CHD [47-49]. Thus, lack of information on the reasons for not returning to work and lack of information concerning giving-up work during the observation period runs the risk of misclassifying the exposure assessment and the related risk estimation. Interestingly, in the Canadian study [31] an additional analysis of CHD patients who discontinued their work career was performed. The results indicated that CHD patients who stopped working for a period of 6 months or longer experienced a somewhat lower risk of recurrent CHD events, compared to those who continued working during the whole observation period (HR $=0.81,95 \%$ CI: 0.34-1.90).

Second, there was not sufficient information on the effect of retirement on CHD across the studies. Of the 4 studies in our review, only 1 study stated that none of the participants had been retired [29]. In the case of the other studies it remains unclear whether some participants had early retirement or received disability pension during the follow-up period. Since the exposure to work stress is discontinued at the moment of retirement, accordingly, the risk of CHD is expected to be decreased. Alternatively, other sources of stress originating from the transition into retirement may be present, such as loss of status and feeling of worthlessness. Some new prospective 
investigations observed that retirement would increase the risk of CHD [50-52]. However, different patterns of health trajectory after statutory retirement vs. retirement due to ill health were also observed [53]. As a result, for early retirees and disability pensioners with CHD, it is difficult to disentangle whether elevated risks of recurrent CHD events are due to the stress at work, stress associated with retirement or conditions related to the 1st CHD itself.

Third, the timing of measuring work stress is critical. Two studies measured work stress after the patients with the 1st CHD returned to work [20,22,31]. In these cases, work stress referred to the conditions experienced after the 1st CHD. By contrast, the other 2 studies measured work stress within 2 weeks following the onset of 1st CHD (even still during the hospitalization period) [21,29], and therefore, assessed work stress experienced before the onset of the 1st CHD. We assume that there are significant changes in the perception and evaluation of psychosocial working conditions by patients, depending on whether they refer to their situation before or after having experienced a significantly threatening life event i.e., a CHD incidence.

Moreover, results of the studies on associations between work stress and CHD vary according to the number of exposure assessments. There is a clear indication that repeated measures of work stress improve the risk estimation, compared to a single exposure assessment [54]. The Canadian study $[22,31]$ supports this notion. A single measure of job strain at time 1 (6 weeks after return to work following the 1 st CHD) or at time 2 (2 years after the 1 st CHD) did not significantly predict recurrent $\mathrm{CHD}$ events $(\mathrm{HR}=1.45$, 95\% CI: 0.82-2.58; and HR $=1.33$, 95\% CI: 0.75-2.34, respectively). However, chronic job strain (exposure to job strain at both time points) was associated with a considerable increase in the risk of recurrent CHD events $(\mathrm{HR}=2.38,95 \% \mathrm{CI}: 1.37-4.13)$.

Fourth, so far, the measurement of work stress was mainly based on the Demand-Control model [17] or the
Effort-Reward Imbalance model [18]. Future studies should enlarge the range of predictors related to an adverse psychosocial work environment. For instance, organizational justice, a model focusing on employees' perceptions of fairness in the workplace [55], was associated with a reduced risk of the 1st CHD in 2 prospective studies [56,57]. Job insecurity [58,59] and overtime work [60] are additional relevant factors in this context.

Fifth, given significant gender differences in work stress [61], in the prevalence and incidence of CHD [12] as well as in the strength of effects of work stress on CHD [13-16], this issue deserves more intense inquiry. In the studies included in our review, men accounted for more than $80 \%$ of the total sample. As mentioned, due to the small number of studies, we were not able to analyze gender differences in work stress and recurrent CHD events. However, in the Swedish study restricted to women only, it is of interest to note that work stress was associated with the elevated risk of recurrent CHD events but did not reach statistical significance, whereas marital stress did predict adverse outcomes [20]. A challenging task of future research relates to the analysis of double exposure to work stress and family stress in women suffering from $\mathrm{CHD}$ and their potential adverse effect on cardiac recurrence.

Finally, while heterogeneity between the selected studies and publication bias were not detected in our meta-analysis, one needs to bear in mind that the presence of bias cannot be ruled out, given the fact that the low number of studies compromises the statistical power of bias assessment $[62,63]$. This methodological limitation can be extended by a limitation related to the generalization of the reported findings. All empirical evidence is restricted to CHD populations returning to work in 2 Western countries, Sweden and Canada. In view of the current socioeconomic and epidemiologic transition in rapidly developing countries, work stress [64] and CHD [65,66] in these regions have become pandemic during the past 2 decades. Therefore, respective evidence on the role of work stress 
in influencing the onset and the recurrence of $\mathrm{CHD}$ events is urgently needed.

\section{CONCLUSIONS}

In conclusion, despite these limitations, our systematic review and meta-analysis support the notion that stressful work in terms of high demand and low control, or of high effort and low reward, is associated with a significantly increased relative risk of recurrent cardiac events in men and women with the first CHD. From a preventive perspective, interventions in the workplace that aim at reducing work stress by improving the psychosocial work environment are warranted $[67,68]$, not only for healthy workers, but also for employees working with CHD. Nevertheless, due to the limited literature available, more well-designed research is needed to examine the associations between work stress and recurrent CHD events in the future, particularly from other regions of the world, such as non-western societies.

\section{REFERENCES}

1. Smith Jr. SC. Reducing the global burden of ischemic heart disease and stroke: A challenge for the cardiovascular community and the United Nations. Circulation. 2011;124(3):278-9, http://dx.doi.org/10.1161/CIRCULATIONAHA.111.040170.

2. Lim GB. Public health: Global burden of cardiovascular disease. Nat Rev Cardiol. 2013;10(2):59, http://dx.doi. org/10.1038/nrcardio.2012.194.

3. Greenwood DC, Muir KR, Packham CJ, Madeley RJ. Coronary heart disease: A review of the role of psychosocial stress and social support. J Public Health Med. 1996;18(2):221-31, http://dx.doi.org/10.1093/oxfordjournals.pubmed.a024483.

4. Kuper H, Marmot M, Hemingway H. Systematic review of prospective cohort studies of psychosocial factors in the etiology and prognosis of coronary heart disease. Semin Vasc Med. 2002;2(3):267-314, http://dx.doi. org/10.1055/s-2002-35401.
5. Neylon A, Canniffe C, Anand S, Kreatsoulas C, Blake GJ, Sugrue D, et al. A global perspective on psychosocial risk factors for cardiovascular disease. Prog Cardiovasc Dis. 2013;55(6):574-81, http://dx.doi.org/10.1016/j.pcad. 2013.03.009.

6. Steptoe A, Kivimäki M. Stress and cardiovascular disease: An update on current knowledge. Ann Rev Public Health. 2013;34:337-54, http://dx.doi.org/10.1146/annurevpublhealth-031912-114452.

7. Meijer A, Conradi HJ, Bos EH, Thombs BD, van Melle JP, de Jonge P. Prognostic association of depression following myocardial infarction with mortality and cardiovascular events: A meta-analysis of 25 years of research. Gen Hosp Psychiatry. 2011;33(3):203-16, http://dx.doi.org/10. 1016/j.genhosppsych.2011.02.007.

8. Roest AM, Martens EJ, Denollet J, de Jonge P. Prognostic association of anxiety post myocardial infarction with mortality and new cardiac events: A meta-analysis. Psychosom Med. 2010;72(6):563-9, http://dx.doi.org/10.1097/ PSY.0b013e3181dbff97.

9. Grande G, Romppel M, Barth J. Association between type D personality and prognosis in patients with cardiovascular diseases: A systematic review and meta-analysis. Ann Behav Med. 2012;43(3):299-310, http://dx.doi.org/10. 1007/s12160-011-9339-0.

10. Georgiades A, Janszky I, Blom M, László KD, Ahnve S. Financial strain predicts recurrent events among women with coronary artery disease. Int J Cardiol. 2009;135(2): 175-83, http://dx.doi.org/10.1016/j.ijcard.2008.03.093.

11. Shah SJ, Krumholz HM, Reid KJ, Rathore SS, Mandawat A, Spertus JA, et al. Financial stress and outcomes after acute myocardial infarction. PLoS One. 2012;7(10):e47420, http://dx.doi.org/10.1371/journal.pone.0047420.

12. Yusuf S, Reddy S, Ônpuu S, Anand S. Global burden of cardiovascular diseases. Part I: General considerations, the epidemiologic transition, risk factors, and impact of urbanization. Circulation. 2001;104(22):2746-53, http://dx.doi. org/10.1161/hc4601.099487. 
13. Belkic K, Landsbergis PA, Schnall PL, Baker D. Is job strain a major source of cardiovascular disease risk? Scand J Work Environ Health. 2004;30(2):85-128, http://dx.doi. org/10.5271/sjweh.769.

14. Kivimäki M, Virtanen M, Elovainio M, Kouvonen A, Väänänen A, Vahtera J. Work stress in the etiology of coronary heart disease - A meta-analysis. Scand J Work Environ Health. 2006;32(6):431-42, http://dx.doi.org/10.5271/ sjweh.1049.

15. Backé EM, Seidler A, Latza U, Rossnagel K, Schumann B. The role of psychosocial stress at work for the development of cardiovascular diseases: A systematic review. Int Arch Occup Environ Health. 2012;85(1):67-79, http://dx.doi. org/10.1007/s00420-011-0643-6.

16. Kivimäki M, Nyberg ST, Batty GD, Fransson EI, Heikkilä K, Alfredsson L, et al. Job strain as a risk factor for coronary heart disease: A collaborative meta-analysis of individual participant data. Lancet. 2012;380(9852):1491-7, http://dx.doi.org/10.1016/S0140-6736(12)60994-5.

17. Karasek R, Theorell T. Healthy work: Stress, productivity, and the reconstruction of working life. New York: Basic Books; 1990. p. 1-381.

18. Siegrist J. Adverse health effects of high-effort/low-reward conditions. J Occup Health Psychol. 1996;1(1):27-41, http:// dx.doi.org/10.1037/1076-8998.1.1.27.

19. Hlatky MA, Lam LC, Lee KL, Clapp-Channing NE, Williams RB, Pryor DB, et al. Job strain and the prevalence and outcome of coronary artery disease. Circulation. 1995;92(3):327-33, http://dx.doi.org/10.1161/01.CIR. 92.3.327.

20. Orth-Gomér K, Wamala SP, Horsten M, Schenck-Gustafsson K, Schneiderman N, Mittleman MA. Marital stress worsens prognosis in women with coronary heart disease: The Stockholm Female Coronary Risk Study. JAMA. 2000;284(23):3008-14, http://dx.doi.org/10.1001/ jama.284.23.3008.

21. László KD, Ahnve S, Hallqvist J, Ahlbom A, Janszky I. Job strain predicts recurrent events after a first acute myocardial infarction: The Stockholm Heart Epidemiology Program. J Intern Med. 2010;267(6):599-611, http://dx.doi. org/10.1111/j.1365-2796.2009.02196.x.

22. Aboa-Éboulé C, Brisson C, Maunsell E, Bourbonnais R, Vézina M, Milot A, et al. Effort-reward imbalance at work and recurrent coronary heart disease events: A 4-year prospective study of post-myocardial infarction patients. Psychosom Med. 2011;73(6):436-47, http://dx.doi.org/10.1097/ PSY.0b013e318222b2d8.

23. Stroup DF, Berlin JA, Morton SC, Olkin I, Williamson GD, Rennie D, et al. Meta-analysis of observational studies in epidemiology: A proposal for reporting. Meta-analysis of Observational Studies in Epidemiology (MOOSE) group. JAMA. 2000;283(15):2008-12， http://dx.doi.org/10.1001/ jama.283.15.2008.

24. Moher D, Liberati A, Tetzlaff J, Altman DG; The PRISMA Group. Preferred reporting items for systematic reviews and meta-analyses: The PRISMA Statement. PLoS Med. 2009;6(7):e1000097, http://dx.doi.org/10.1371/journal. pmed.1000097.

25. Hedges LV, Vevea JL. Fixed- and random-effects models in meta-analysis. Psychol Methods. 1998;3(4):486-504, http://dx.doi.org/10.1037/1082-989X.3.4.486.

26. Higgins JPT, Thompson SG, Deeks JJ, Altman DG. Measuring inconsistency in meta-analyses. BMJ. 2003;327 (7414):557-60, http://dx.doi.org/10.1136/bmj.327.7414.557.

27. Begg CB, Mazumdar M. Operating characteristics of a rank correlation test for publication bias. Biometrics. 1994;50(4):1088-101, http://dx.doi.org/10.2307/2533446.

28. Sterne J. Meta-Analysis in STATA: An Updated Collection from the Stata Journal. USA: Stata Press; 2009. p. 1-259.

29. Theorell T, Perski A, Orth-Gomér K, Hamsten A, de Faire U. The effects of the strain of returning to work on the risk of cardiac death after a first myocardial infarction before the age of 45. Int J Cardiol. 1991;30(1):61-7, http://dx.doi.org/10.1016/0167-5273(91)90125-9.

30. Leander K, Wiman B, Hallqvist J, Andersson T, Ahlbom A, de Faire U. Primary risk factors influence risk 
of recurrent myocardial infarction/death from coronary heart disease: Results from the Stockholm Heart Epidemiology Program (SHEEP). Eur J Cardiovasc Prev Rehabil. 2007;14(4):532-7, http://dx.doi.org/10.1097/ HJR.0b013e328012e3cc.

31. Aboa-Éboulé C, Brisson C, Maunsell E, Mâsse B, Bourbonnais $R$, Vézina $M$, et al. Job strain and risk of acute recurrent coronary heart disease events. JAMA. 2007;298(14): 1652-60, http://dx.doi.org/10.1001/jama.298.14.1652.

32. Bairati I, Roy L, Meyer F. Measurement errors in standard visual analysis of coronary angiograms: Consequences on clinical trials. Can J Cardiol. 1993;9(3):225-30.

33. Pickering TG. Should studies of patients undergoing coronary angiography be used to evaluate the role of behavioral risk factors for coronary heart disease? J Behav Med. 1985;8(3):203-13, http://dx.doi.org/10.1007/ BF00870308.

34. Karasek R, Brisson C, Kawakami N, Houtman I, Bongers P, Amick B. The Job Content Questionnaire (JCQ): An instrument for internationally comparative assessments of psychosocial job characteristics. J Occup Health Psychol. 1998;3(4):322-55, http://dx.doi.org/10.1037/1076-8998. 3.4.322.

35. Chungkham HS, Ingre M, Karasek R, Westerlund H, Theorell T. Factor structure and longitudinal measurement invariance of the demand control support model: An evidence from the Swedish Longitudinal Occupational Survey of Health (SLOSH). PLoS One. 2013;8(8):e70541, http:// dx.doi.org/10.1371/journal.pone.0070541.

36. Siegrist J, Starke D, Chandola T, Godin I, Marmot M, Niedhammer I, et al. The measurement of effort-reward imbalance at work: European comparisons. Soc Sci Med. 2004;58(8):1483-99, http://dx.doi.org/10.1016/S02779536(03)00351-4.

37. Aboa-Éboulé C, Brisson C, Blanchette C, Maunsell E, Bourbonnais R, Abdous B, et al. Effort-reward imbalance at work and psychological distress: A validation study of post-myocardial infarction patients. Psychosom
Med. 2011;73(6):448-55, http://dx.doi.org/10.1097/01.PSY. 0000399790.82499.d7.

38. Chandola T, Heraclides A, Kumari M. Psychophysiological biomarkers of workplace stressors. Neurosci Biobehav Rev. 2010;35(1):51-7, http://dx.doi.org/10.1016/j.neubiorev. 2009.11.005.

39. Jarczok MN, Jarczok M, Mauss D, Koenig J, Li J, Herr RM, et al. Autonomic nervous system activity and workplace stressors - A systematic review. Neurosci Biobehav Rev. 2013;37(8):1810-23, http://dx.doi.org/10.1016/ j.neubiorev.2013.07.004.

40. Buccelletti E, Gilardi E, Scaini E, Galiuto L, Persiani R, Biondi A, et al. Heart rate variability and myocardial infarction: Systematic literature review and metanalysis. Eur Rev Med Pharmacol Sci. 2009;13(4):299-307.

41. Jutla SK, Yuyun MF, Quinn PA, Ng LL. Plasma cortisol and prognosis of patients with acute myocardial infarction. J Cardiovasc Med (Hagerstown). 2014;15(1):33-41, http:// dx.doi.org/10.2459/JCM.0b013e328364100b.

42. Nakata A. Psychosocial job stress and immunity: A systematic review. Methods Mol Biol. 2012;934:39-75, http:/ dx.doi.org/10.1007/978-1-62703-071-7_3.

43. Simon T, Taleb S, Danchin N, Laurans L, Rousseau B, Cat$\tan \mathrm{S}$, et al. Circulating levels of interleukin-17 and cardiovascular outcomes in patients with acute myocardial infarction. Eur Heart J. 2013;34(8):570-7, http://dx.doi. org/10.1093/eurheartj/ehs263.

44. Siegrist J, Rödel A. Work stress and health risk behavior. Scand J Work Environ Health. 2006;32(6):473-81, http:// dx.doi.org/10.5271/sjweh.1052.

45. Leineweber C, Kecklund G, Janszky I, Ákerstedt T, OrthGomér K. Poor sleep increases the prospective risk for recurrent events in middle-aged women with coronary disease. The Stockholm Female Coronary Risk Study. J Psychosom Res. 2003;54(2):121-7, http://dx.doi.org/10.1016/S0022-3999 (02)00475-0.

46. Hayano J, Carney RM, Watanabe E, Kawai K, Kodama I, Stein PK, et al. Interactive associations of depression and 
sleep apnea with adverse clinical outcomes after acute myocardial infarction. Psychosom Med. 2012;74(8):832-9, http://dx.doi.org/10.1097/PSY.0b013e31826d2c81.

47. Fukuoka Y, Dracup K, Takeshima M, Ishii N, Makaya M, Groah L, et al. Effect of job strain and depressive symptoms upon returning to work after acute coronary syndrome. Soc Sci Med. 2009;68(10):1875-81, http://dx.doi. org/10.1016/j.socscimed.2009.02.030.

48. Du CL, Cheng Y, Hwang JJ, Chen SY, Su TC. Workplace justice and psychosocial work hazards in association with return to work in male workers with coronary heart diseases: A prospective study. Int J Cardiol. 2013;166(3):745-7, http:// dx.doi.org/10.1016/j.ijcard.2012.09.176.

49. Worcester MU, Elliott PC, Turner A, Pereira JJ, Murphy BM, le Grande MR, et al. Resumption of work after acute coronary syndrome or coronary artery bypass graft surgery. Heart Lung Circ. 2014;23(5):444-53.

50. Behncke S. Does retirement trigger ill health? Health Econ. 2012;21(3):282-300, http://dx.doi.org/10.1002/hec.1712.

51. Moon JR, Glymour MM, Subramanian SV, Avendaño M, Kawachi I. Transition to retirement and risk of cardiovascular disease: Prospective analysis of the US health and retirement study. Soc Sci Med. 2012;75(3):526-30, http://dx.doi. org/10.1016/j.socscimed.2012.04.004.

52. Olesen K, Rugulies R, Rod NH, Bonde JP. Does retirement reduce the risk of myocardial infarction? A prospective registry linkage study of 617511 Danish workers. Int J Epidemiol. 2014;43(1):160-7, http://dx.doi.org/10.1093/ije/dyt260.

53. Jokela M, Ferrie JE, Gimeno D, Chandola T, Shipley MJ, Head J, et al. From midlife to early old age: Health trajectories associated with retirement. Epidemiology. 2010;21(3): 284-90, http://dx.doi.org/10.1097/EDE.0b013e3181d61f53.

54. Kivimäki M, Head J, Ferrie JE, Brunner E, Marmot MG, Vahtera $\mathrm{J}$, et al. Why is evidence on job strain and coronary heart disease mixed? An illustration of measurement challenges in the Whitehall II study. Psychosom Med. 2006;68(3):398-401, http://dx.doi.org/10.1097/01.psy. 0000221252.84351.e2.
55. Elovainio M, Heponiemi T, Sinervo T, Magnavita N. Organizational justice and health; Review of evidence. G Ital Med Lav Ergon. 2010;32(3 Suppl B):B5-9.

56. Kivimäki M, Ferrie JE, Brunner E, Head J, Shipley MJ, Vahtera J, et al. Justice at work and reduced risk of coronary heart disease among employees: The Whitehall II Study. Arch Intern Med. 2005;165(19):2245-51, http://dx.doi.org/ 10.1001/archinte.165.19.2245.

57. Elovainio M, Leino-Arjas P, Vahtera J, Kivimäki M. Justice at work and cardiovascular mortality: A prospective cohort study. J Psychosom Res. 2006;61(2):271-4, http://dx.doi.org/ 10.1016/j.jpsychores.2006.02.018.

58. Virtanen M, Nyberg ST, Batty GD, Jokela M, Heikkilä K, Fransson EI, et al. Perceived job insecurity as a risk factor for incident coronary heart disease: Systematic review and meta-analysis. BMJ. 2013;347:f4746, http://dx.doi.org/10.1136/ bmj.f4746.

59. László KD, Engström K, Hallqvist J, Ahlbom A, Janszky I. Job insecurity and prognosis after myocardial infarction: The SHEEP Study. Int J Cardiol. 2013;167(6):2824-30, http://dx.doi.org/10.1016/j.ijcard.2012.07.005.

60. Virtanen M, Heikkilä K, Jokela M, Ferrie JE, Batty GD, Vahtera J, et al. Long working hours and coronary heart disease: A systematic review and meta-analysis. Am J Epidemiol. 2012;176(7):586-96, http://dx.doi.org/10.1093/aje/ kws139.

61. Campos-Serna J, Ronda-Pérez E, Artazcoz L, Moen BE, Benavides FG. Gender inequalities in occupational health related to the unequal distribution of working and employment conditions: A systematic review. Int J Equity Health. 2013;12(1):57, http://dx.doi.org/10.1186/1475-9276-12-57.

62. Colditz GA, Burdick E, Mosteller F. Heterogeneity in meta-analysis of data from epidemiologic studies: A commentary. Am J Epidemiol. 1995;142(4):371-82.

63. Palma S, Delgado-Rodriguez M. Assessment of publication bias in meta-analyses of cardiovascular diseases. J Epidemiol Community Health. 2005;59(10):864-9, http://dx.doi.org/ 10.1136/jech.2005.033027. 
64. Kortum E, Leka S, Cox T. Psychosocial risks and workrelated stress in developing countries: Health impact, priorities, barriers and solutions. Int J Occup Med Environ Health. 2010;23(3):225-38, http://dx.doi.org/10.2478/ v10001-010-0024-5.

65. Yusuf S, Reddy S, Öunpuu S, Anand S. Global burden of cardiovascular diseases. Part II: Variations in cardiovascular disease by specific ethnic groups and geographic regions and prevention strategies. Circulation. 2001;104(23): 2855-64, http://dx.doi.org/10.1161/hc4701.099488.

66. Kim AS, Johnston SC. Global variation in the relative burden of stroke and ischemic heart disease.
Circulation. 2011;124(3):314-23, http://dx.doi.org/10.1161/ CIRCULATIONAHA.111.018820.

67. Lamontagne AD, Keegel T, Louie AM, Ostry A, Landsbergis PA. A systematic review of the job-stress intervention evaluation literature, 1990-2005. Int J Occup Environ Health. 2007;13(3):268-80, http://dx.doi.org/10.1179/ oeh.2007.13.3.268.

68. Montano D, Hoven H, Siegrist J. Effects of organisational-level interventions at work on employees' health: A systematic review. BMC Public Health. 2014;14(1):135, http://dx.doi.org/10.1186/1471-2458-14-135.

This work is available in Open Access model and licensed under a Creative Commons Attribution-NonCommercial 3.0 Poland License - http://creativecommons.org/ licenses/by-nc/3.0/pl/deed.en. 